\title{
POR QUE O AFETO É IMPORTANTE PARA A POLÍTICA? IMPLICAÇÕES TEÓRICO-ESTRATÉGICAS
}

\author{
WHY IS AFFECT IMPORTANT TO POLITICS? THEORETICAL-STRATEGIC \\ IMPLICATIONS
}

\section{¿POR QUÉ EL AFECTO ES IMPORTANTE PARA LA POLÍTICA? IMPLICACIONES TEÓRICO-ESTRATÉGICAS}

Veronica Borges

Universidade do Estado do Rio de Janeiro - Brasil

Alice Casimiro Lopes

Universidade do Estado do Rio de Janeiro - Brasil

\begin{abstract}
Resumo: O presente trabalho reivindica o afeto como mais uma dimensão a ser considerada na produção das políticas curriculares em sua condição constitutiva. Propõe um debate acerca das implicações teórico-estratégicas dos afetos a partir da incorporação da perspectiva discursiva de Ernesto Laclau e Chantal Mouffe. Para tal empreitada, opera com as lógicas do social e do político, como também a partir da lógica fantasmática, seguindo a argumentação de Jason Glynos e David Howarth. Num duplo gesto, essa argumentação coloca em causa a naturalização do caráter paradigmático do pensamento cartesiano e argumenta em defesa das práticas articulatórias como uma opção teórico-estratégica para pôr a significação em movimento e explorar jogos de linguagem que deem passagem aos afetos na política.
\end{abstract}

Palavras chave: afeto; política de currículo; teoria do discurso.

\begin{abstract}
The present paper claims affect as another dimension to be considered in the production of curricular policies in their constitutive condition. It proposes a debate about the theoretical-strategic implications of affects from the incorporation of the discursive perspective of Ernesto Laclau and Chantal Mouffe. For such an undertaking, it operates with the logics of the social and political, as well as from the fantasmatic logic, following the arguments of Jason Glynos and David Howarth. In a double gesture, it calls into question the naturalization of the paradigmatic character of Cartesian thought and argues in defense of articulatory practices as a theoretical-strategic way to put meaning in motion and explore language games that give way to affects in politics.
\end{abstract}

Keywords: affect; curriculum policy; theory of discourse.

Resumen: El presente trabajo reivindica el afecto como otra dimensión a considerar en la producción de políticas curriculares en su condición constitutiva. Propone un debate sobre las implicaciones teóricoestratégicas de los afectos desde la incorporación de la perspectiva discursiva de Ernesto Laclau y Chantal Mouffe. Para tal empresa, opera con la lógica de lo social y lo político, así como desde la lógica 
fantasmática, siguiendo los argumentos de Jason Glynos y David Howarth. En un doble gesto cuestionamos la naturalización del carácter paradigmático del pensamiento cartesiano y argumentamos en defensa de las prácticas articulatorias como vía teórico-estratégica para poner en movimiento el significado y explorar juegos de lenguaje que dan paso a los afectos en la política.

Palabras clave: afecto; política curricular; teoría del discurso.

\section{Situando a problemática}

Iniciamos este trabalho com uma provocação: como falar de estratégias de investigação sem considerar a tradição cartesiana e sua arquitetura racional recebida como legado da modernidade? Com essa provocação, queremos argumentar o quanto a disseminação da metafísica cartesiana e de seus espectros - reverberações de toda ordem por meio, por exemplo, das ideias de método/metodologia, de regras para a pesquisa envolvendo critérios de generalização - tem criado constrangimentos para as pesquisas com foco no currículo, especialmente para as pesquisas vinculadas ao pós-estruturalismo e ao pós-fundacionalismo. Ao mesmo tempo, situamos o quanto não se pode apagar ou superar uma herança, o quanto o abandono da metafísica é impossível.

Em nossas investigações, inúmeras vezes somos convocadas a responder a esse enquadramento, a responder a uma concepção de mundo que opera com excessivo ordenamento, normatividade, disciplina, controle, hierarquia, decomposição, atomização, homogeneidade, com vistas a produzir universais. Não bastasse isso, e em duplo gesto, também respondemos a uma concepção de sujeito enredado em sua essência, centrado, racional e polarizado. Insistimos nesse preâmbulo por entendermos que vem sendo retomada a contribuição de Descartes (BOVE, 2009) na noção de intelecto, de um “eu” responsável por seus próprios atos e ações e que deixa marcas no social (sociedade), para dizê-lo de modo simples. O pensamento cartesiano imprimiu e ainda imprime uma inflexão importante na concepção do sujeito da razão e, simultaneamente, se esquivou sobremaneira da ideia de que as paixões "afetam" os corpos.

Situando a tradição da grande área das Ciências Humanas, Laurent Bove contribui para pensarmos sobre o "lugar" das paixões em Descartes, passando pela leitura realizada por Espinosa:

Um pouco antes de Espinosa, no Tratado sobre as paixões, a partir de um ponto de vista um pouco diferente, Descartes havia tentado algo semelhante: tratar as paixões como algo que tem a ver com o físico, com o corporal. O seu livro marca o início desse empreendimento de laicização, ou de naturalização, 
dos sentimentos e das paixões. Espinosa - em geral um crítico agudo das insuficiências de Descartes - afirma que neste caso seu predecessor começou bem, mas se perdeu no meio do caminho, porque sofria de três preconceitos fundamentais, matriciais, que acabaram viciando seu empreendimento e conduzindo-o ao fracasso. Primeiro e fundamental: Descartes não chega a abandonar por completo uma visão teleológica, finalista - uma visão de mundo que se apoia na pergunta "para quê". Segundo, ele acredita no livre arbítrio. Terceiro, repete algo que vem desde Platão, e foi se tornando difundido por meio da religião, do cristianismo e de outras visões religiosas: que existe uma dualidade entre a alma e o corpo. (BOVE, 2009, p. 2)

Importante destacar que, ainda segundo Bove (2009), Descartes não avança em seu empreendimento de "tratar as paixões como algo que tem a ver com o físico, com o corporal" por diferentes motivações, sejam elas os constrangimentos religiosos, por manter-se na lógica teleológica, seja pela defesa de que o sujeito "é senhor em sua casa”. Consideramos pertinente recuperar Baruch Espinosa como um teórico emblemático, quer pelas críticas a Descartes, quer pelo investimento nos afetos. Faz-se mister destacar que, ainda que o teórico reconheça no pensamento cartesiano um esforço em retirar do plano da transcendência (leis divinas) as motivações do sujeito, realça também o quanto acaba por edificar o humano sob o jugo da razão, dada a força que o "eu" soberano ganha em seu pensamento. Esse processo tem como efeito "a aderência discursiva" entre ser humano, razão e transcendência - o ser humano racional reocupa a transcendência. Espinosa, por sua vez, recusa tanto a transcendência quanto a condição de ser humano consciente - e põe em causa o livre arbítrio.

Dando um salto que nos interessa particularmente neste trabalho, é importante notar que essa crítica ao livre arbítrio foi incorporada por Freud (BOVE, 2009) como também por Lacan. Ambos os psicanalistas reconhecem uma proximidade com a teoria dos afetos espinosista, ainda que tenham distanciamentos e operem com essa noção de modo completamente diferente. Com essas discussões trazidas até aqui, procuramos enunciar nossa pretensão de nos afastar daquelas concepções apoiadas nas filosofias do sujeito, que operam com a dualidade corpo-alma e se apoiam no pressuposto de uma separação entre razão e paixões.

Ainda tentando acentuar a problematização do pensamento cartesiano, ao invés de chancelarmos a expressão "penso, logo existo", nossa aposta vai no sentido de acompanhar as críticas de Espinosa ${ }^{1}$ no que se refere a sua recusa do princípio do livre arbítrio. Assumimos, com Freud e especialmente com Lacan, a recolocação do debate em outros termos, nos termos de uma ontologia negativa como enunciada pela expressão "sou, onde não penso; penso, onde não sou” (FINK, 1998).

\footnotetext{
${ }^{1}$ Vale destacar que, no que se refere a Espinosa, não incorporamos a teoria dos afetos como um todo. Por exemplo, rejeitamos a centralidade no plano de imanência.
} 
Num duplo gesto, que sabemos ousado em suas pretensões difíceis de serem realizadas nos limites de um artigo - este é um trabalho para uma vida inteira -, colocamos em causa a naturalização desse caráter paradigmático e tentamos explorar outros modos de pensar o sujeito, o conhecimento, a pesquisa, a relação teoria-prática. Temos a pretensão de oferecer outras noções de pesquisa que assumam as críticas ao pensamento cartesiano e a suas reverberações, acentuando a importância dos afetos nas pesquisas. Fazemos isso ao operar com a perspectiva da teoria do discurso no campo do currículo.

Não consideramos ser esta a única porta de entrada para valorizar os afetos nas pesquisas em educação, particularmente focalizando o currículo. Não há caminhos e opções únicas na perspectiva assumida por nós. Situamos, por exemplo, os trabalhos de Carvalho, Kretli e Delboni (2016) e Matus (2016) como outros caminhos possíveis para esse intento. Esses trabalhos apresentam investigações que se afastam do lugar-comum da busca de representação mais consistente, fazendo um esforço em elaborar metodologias outras para investigar, as quais passam por um mergulho no dia a dia, no vivido, no local, com foco no relacional, no currículorelação (CARVALHO; KRETLI; DELBONI, 2016) ou em reconfigurar a problemática investigada, a partir da compreensão de que a realidade não "está lá" para ser apreendida (MATUS, 2016). Ambos os trabalhos reafirmam o quanto o currículo produz subjetividades e a investigação deve ser instada a ser criativa, a fim de acompanhar essas trajetórias e seus efeitos.

Sustentamos também que não apenas essas abordagens tangenciam as preocupações aqui apresentadas. Há uma busca crescente na comunidade de curriculistas por abordagens teórico-metodológicas que possam enfrentar os aportes canônicos da herança moderna, tais como as constantes problematizações dos binarismos mais evidentes como teoria/prática, científico/senso comum, indivíduo/sociedade, razão/afeto, entre tantos outros ${ }^{2}$. Ao mesmo tempo assumimos, como integrantes dessa comunidade de curriculistas, ser sempre possível e necessário nos perguntarmos em que medida nossas investigações teórico-metodológicas se afastam ou não dessa herança, como essas marcas se fazem presentes-ausentes.

Tendo em vista essas premissas, afirmamos neste artigo as contingências de nossas trajetórias que envolvem a defesa da abordagem dos afetos na pesquisa em política de currículo por meio da perspectiva discursiva abraçada por nós. É por meio dessa perspectiva que defendemos a validade de des-sedimentar como a apropriação dos discursos em prol da racionalidade ganharam passagem. Nossa posição é que os afetos são, em igual medida,

\footnotetext{
${ }^{2}$ Ver, por exemplo, os livros com os trabalhos encomendados apresentados no GT12 - Currículo | ANPEd
} 
constitutivos dos processos de conhecer em sua tentativa de tentar representar o mundo. Mais especificamente, interessa-nos pensar sobre quais seriam os efeitos de se fazer pesquisa contornando e por vezes abalroando o pensamento cartesiano e afirmando os questionamentos pós-estruturais e pós-fundacionais. Mais uma vez, buscamos operar com o currículo a partir do constante e podemos dizer também eterno - não se trata de modelos superados de uma vez por todas - questionamento de registros amplamente difundidos pela modernidade: status de verdade, objetivismo, determinismo, essencialismo, centralidade do sujeito, racionalismo.

Nosso desafio mais específico neste trabalho implica esvaziar o lócus da racionalidade metafísica, sobretudo cartesiana, nas políticas curriculares. Ao mesmo tempo, oferecemos um debate teórico-estratégico que reivindica o afeto como mais uma dimensão a ser considerada na produção das políticas curriculares em sua condição constitutiva. De certa forma, nossa interpretação de currículo como texto impõe-nos apresentar e discutir implicações teóricoestratégicas do investimento afetivo nas políticas curriculares.

Tal movimento é realizado aqui a partir da incorporação da perspectiva discursiva de Ernesto Laclau e Chantal Mouffe (1990; 2011; 1985), principalmente, mas não somente, com as lógicas do social e do político, como também a partir da incorporação da lógica fantasmática, seguindo a argumentação de Jason Glynos e David Howarth (2007), visando ampliar ainda mais as possibilidades de interpretação e pesquisa em uma perspectiva discursiva. Procuramos argumentar que esse movimento de incorporação é possível, na medida em que a psicanálise vem sendo incorporada pelo teoria do discurso via diferentes noções. Mais enfaticamente fixamo-nos no conceito de Real, com vistas a situar que este opera tanto pela ontologia da negatividade como também pela positividade.

\section{Os afetos são importantes para a política?}

Esperamos já ter deixado claros, por este e outros textos (LOPES, 2014; 2018; LOPES; BORGES, 2015; LOPES; MACEDO, 2012) nossa vinculação aos questionamentos acerca de como o cientificismo arvora-se em descrever e compreender a realidade através de metodologias baseadas em leis causais. Argumentamos que esse discurso falha, continuadamente, nessa empreitada quando a experiência do conhecimento fica atrelada à razão. Ao fazer isso, coloca (tentativamente) força no princípio da neutralidade das decisões (livre arbítrio) e anuncia ser possível apreender a realidade e domesticá-la sob as leis da ciência. Oferece um enquadramento teórico-metodológico capaz de elucidar partes da realidade e alimenta continuamente a evidência científica como a possibilidade de "tudo dizer". A fim de 
acentuar nosso desacordo com essa concepção, vamos direto ao ponto: "contrário ao popular e incondicional otimismo Iluminista, o conhecimento em geral nunca é adequado; algo sempre escapa.” (STAVRAKAKIS, 2007, p. 8, tradução livre).

Como vimos, há vários curriculistas (CARVALHO; KRETLI; DELBONI, 2016; GREEN, 2019; LOPES, 2018 ; 2018b; MACEDO; MILLER, 2018; MATUS, 2016; MILLER, 2014; PINAR, 2003; VEIGA-NETO; MACEDO, 2008) que rejeitam a ideia de a racionalidade científica ser capaz de elucidar a experiência da realidade. Mais do que isso, apresentam possibilidades teórico-estratégicas a partir da crítica a essa centralidade. Se é possível alguma conclusão equivalencial, opaca e fugidia, nesses estudos, é aquela pela qual só temos possibilidade de acessar o social, o mundo, algo que possamos nomear como o sujeito, através da linguagem. Tudo o que está no mundo é constituído discursivamente. Outra afirmação nada trivial é assumir que se trata sempre de uma significação intensa e extensamente disputada. E aí nos mantemos com a indagação que vem nos instigando, e que tentamos abordar por diferentes linhas de investigação, a saber, "como algo sempre escapa”?

Uma possibilidade de resposta a essa questão aponta para a significação em deslocamento. Não estamos negando a fixação de sentidos, certa estabilidade impossível e necessária à política (LOPES, 2018a). Defendemos sim que tal operação é sempre da ordem da contingência radical. Com a inspiração da psicanálise, esse "algo que sempre escapa" está marcado pela contingência radical e se constitui parcialmente, tendo em vista o caráter faltante de qualquer processo de fixação de sentidos. Ainda assim, esse processo não deixa de arregimentar "energias" (catexias) para "signifixações”. Importa destacar que, segundo Glynos (2021), essa ideia de "contingência radical" ressoa em várias categorias de diferentes teorizações com insights muito próximos (ainda que nunca iguais): indecidibilidade derridiana, deslocamento laclauniano, excesso em Deleuze e Guattari, e falta do Outro na psicanálise lacaniana. São tentativas de abordar essa condição fugidia, fluida da significação e que traz consequências teórico-práticas para toda relação com a pesquisa e a produção de conhecimento.

Aqui, de alguma forma buscando acentuar a contribuição da psicanálise, a ideia de apreensão do Real (não da realidade) implica compreender que a realidade, enquanto totalidade, não existe. Só podemos aceder via linguagem às marcas de uma plenitude ausente. Se o que podemos "acionar" são marcas do que já não está, está dada uma "cambalhota" na tentativa objetivista de compreender o mundo e fortalecemos a questão de "como algo sempre escapa".

Tal conclusão traz implicações para nossas investigações. Destacamos entre elas, a busca por uma gramática que possa expressar como determinados discursos ganham ou não 
força, para além ou aquém de qualquer racionalidade. Tal gramática, por sua vez, não é um conjunto de regras pré-estabelecidas, capazes de definir posições e ações dos sujeitos. São regras que se modificam no próprio desenrolar do jogo político (de linguagem), modificando também quem joga e contra quem/que se joga.

Nessa medida, estamos falando de uma abertura ontológica e, mais ainda, do modo como a abertura no sistema de significação constitui o sujeito cindido. Isso é articulado com a fantasia e o gozo, nos dizeres lacanianos, e coloca-nos como desafio investigar os investimentos afetivos nos discursos. Pelas afirmações realizadas até aqui, esperamos ter deixado explícito que não nos alinhamos às críticas realizadas por alguns autores (ZIZEK, 2020; GILBERT, 2004; SALTER, 2016) de que a teoria do discurso não faz o destaque devido às questões do investimento afetivo em suas teorizações. Mais uma vez, acompanhando os estudiosos da Escola de Essex (GLYNOS, 2021; HOWARTH; GLYNOS, 2007; STAVRAKAKIS, 2006; 2007), reiteramos que a oposição entre razão e afeto, recorrente na literatura, tanto foi rejeitada por Jacques Lacan como também por Ernesto Laclau. Ambos se afastam de qualquer ideia de dualidade entre razão e afeto, mesmo que uma dualidade relacional, como também se afastam da ideia de subsunção do afetivo no simbólico/discursivo. Antes, esses autores defendem o caráter mutuamente constitutivo entre investimento afetivo e discurso.

Há um esforço na obra de Laclau em fazer reverberar o caráter constitutivo da linguagem e nisso ele está em alinhamento com a psicanálise lacaniana. Lacan e Laclau também parecem estar alinhados quanto à dimensão radical dessa afirmação: os limites do discurso. Não se trata de um aporte teórico no qual tudo pode, "do assim é se lhes parece" pirandelliano como uma de nós já abordou (LOPES, 2014). Também não se trata de idealismo. Essa condição radical se expressa, porque os limites são constitutivos; há um não apaziguamento constitutivo, uma vez que a falta não será preenchida pela eliminação dos limites. Consideramos bastante esclarecedor acompanhar a argumentação de Glynos e Stavrakakis:

\footnotetext{
Por conseguiente, la distincion antes mencionada entre el ser discursivo y sus límites internos parece ser análoga a la distinción lacaniana entre la "realidade" y lo "real". Em um sentido muy lacaniano la realidade corresponde a la identidade discursivamente construída de los objetos, en tanto que lo real nombra aquello que es impossible articular en el discurso. La realidade es aquello que el sujeto social construye empleando sus recursos simbólicos e imaginarios. (GLYNOS; STAVRAKAKIS, 2008, p. 253)
}

Vale notar que Jacques Lacan não tem como foco a dimensão afetiva em si. Seu foco perpassa por um entendimento particular de afeto e por realçar o caráter constitutivo do simbólico para o ser humano, dimensão já referida na máxima freudiana “o inconsciente funciona como a linguagem". Também importa afirmar que Ernesto Laclau, em várias 
entrevistas nas quais foi indagado acerca do papel do afeto em sua teorização, respondia destacando que o afeto (na figura do objeto a lacaniano) sempre esteve presente em seus trabalhos, nomeadamente, desde Hegemonia e Estratégia Socialista e Razão Populista (LACLAU, 2011; 2009). Para Laclau, o afeto funciona como o "moto" que mobiliza/subverte as demandas diferenciais em demandas equivalenciais. Seria, assim, uma força (energia catexial) capaz de fazer a articulação em torno de um nome - os significantes vazios. Ele destaca também que o intervalo (frágil, debilitado, opaco) entre as demandas particulares e sua possibilidade de alcance universal encontra passagem através do investimento afetivo.

Sem negar a influência e a incorporação de aspectos da teoria psicanalítica, especialmente o afeto, na teoria do discurso, tanto Jason Glynos e David Howarth quanto Yannis Stavrakakis, todos pesquisadores da Escola de Essex, sugerem sentir falta de alguns conceitos lacanianos, como a fantasia e o gozo, considerados por eles como potentes para enfrentarem os questionamentos metodológicos da perspectiva discursiva. Para esses autores, mesmo tendo em vista que determinadas categorias da psicanálise sejam clínicas e não tenham uma contribuição mais substantiva para a teoria do discurso, as noções da psicanálise mencionadas ampliam a possibilidade de investigação e interpretação dos discursos. Ainda para esses autores, Laclau incorpora reiteradamente a noção de Real e a ontologia negativa, mas consideram fazer falta investigar como aquilo que nomeamos social traz essas marcas das reiteradas tentativas de positivar o Real (GLYNOS; STAVRAKAKIS, 2010).

Ao retomarem a problemática entre realidade e Real, os autores (GLYNOS; STAVRAKAKIS, 2010) destacam um aspecto que nos parece ter sido pouco explorado, qual seja, o alcance do Real é incontornável na teoria do discurso. Explorar suas idiossincrasias pode dar respostas, ou ainda melhor, gerar mais perguntas sobre "como algo sempre escapa" e como se dá esse modo de funcionamento dos processos discursivos (que nos subjetivam). Em outras palavras, com vistas a explorarmos um pouco mais nossa pergunta inicial - "como algo sempre escapa" -, estamos considerando que essa impossibilidade é da ordem do Real (daquilo que não tem sentido) e que só encontra alguma passagem nas marcas de uma "positividade": uma positividade fantasmática que se satisfaz na busca de satisfação do desejo.

Na teoria da psicanálise há três registros: o Real, o Simbólico e o Imaginário. O Real seria o não representável, aquilo que resiste à simbolização, é o sem sentido. O Simbólico e o Imaginário operam tentativamente, sempre importante frisar, para positivar os sentidos. No intervalo, no hiato entre Real e realidade, opera-se uma tentativa de significar essa busca por realização do desejo: isso é possível nos registros simbólicos e imaginários, mas mantém-se 
como marcas de uma incompletude ausente. A segunda parte dessa sentença recoloca o Real em sua negatividade, enquanto a primeira parte afirma "certa positividade" (LACLAU, 2011).

$\mathrm{Na}$ teoria discursiva laclauniana, o antagonismo é uma expressão dessa negatividade. A respeito desse tema, Gloria Perelló e Paula Biglieri argumentam:

De este modo, definir al antagonismo como "la presencia del outro que impede ser yo mismo" implica ya alguna forma de inscripción de lo real traumático constitutivo de toda identidad. La possibilidad de establecer una frontera que delimite um nosotros y ellos, es uma forma de "representar lo irrepresentable”. (PERELLÓ; BIGLIERI, 2012, p. 45)

Em Lopes (2018) já foi discutido, a partir do debate de Zizek com Laclau, como esse antagonismo é a expressão de uma das múltiplas formas de identificação visando a impossível tentativa de suprir a falta constitutiva do sujeito. O antagonismo expressa a ilusão do sujeito nas lutas emancipatórias que julga poder alcançar uma identidade plena, caso o exterior com o qual se antagoniza seja aniquilado. É com a noção de deslocamento, a disrupção da ordem simbólica por eventos impossíveis de serem representados, que Laclau (2000) mais estreitamente incorpora a noção de Real lacaniano na teoria do discurso. Como discutem Perelló e Biglieri (2021):

La dislocacíon es el fracaso de que uma estructura se cierre como tal. Com ello, admite que toda identidad (y objeto social) de por sí está dislocada porque depende de um exterior que - a la vez que la niega - es su condición de posibilidad. Dado que el campo de las identidades es relacional porque los sujetos sociales no se constituyen de manera puramente externa (los unos de los otros); las identidades nunca pueden constituirse plenamente, sino que forman um sistema imposible de cerrar que depende sempre de um determinado afuera que lo constituye. (IDEM, p. 47)

A partir daí, consideramos que a noção de antagonismo sofre um giro na teoria do discurso: passa da ideia de limite para a ideia de articulação discursiva e pode ser alinhado às dimensões simbólica e imaginária. Há também a positividade do Real: não podemos somente falar em interrupção, disrupção do discurso, e que este carece de possibilidades simbólicas de significação, e ainda, que se trata de uma falta do Real, "en particular la falta de jouissance real" (GLYNOS, STAVRAKAKIS, 2010, p. 255). Ao nosso ver, essa parece ser uma pista a ser considerada, com implicações para "as questões metodológicas". Esta é uma pista vinculada a uma parte da argumentação que subsidia nossas preocupações teórico-estratégicas: o modo de expressar essa falta do Real só pode emergir positivada, ou seja, imaginarizada via fantasia (objeto pequeno a). Na psicanálise, a fantasia ocupa um duplo lugar: o de tamponar a falta constitutiva do Outro e o de se colocar como aquilo que vai recuperar o gozo (desde sempre perdido). 
Nossa pretensão, no âmbito de nossas pesquisas no campo das políticas curriculares, passa ser a de explorar como podemos dar consequência a essas discussões da negatividade e positividade do Real, principalmente via significante vazio, focalizando um pouco mais em como os afetos são importantes para a política. Ao fazer isso estamos também trazendo para a discussão outras noções da psicanálise como o gozo (jouissance) e a fantasia. Na próxima seção, passaremos a apresentar a abordagem das lógicas com vistas a expressar mais enfaticamente a força do "afeto" - como uma fantasia constitutiva que adere às práticas discursivas nas arenas de disputas por significações no campo das políticas curriculares.

A abordagem das lógicas de Jason Glynos e David Howarth, notadamente a lógica fantasmática, nos inspira nessa direção. Com isso, seguimos as pistas deixadas por Laclau e Mouffe e seus principais colaboradores da Escola de Essex. Esses autores muito têm contribuído na produção teórico-estratégica que vem nos possibilitando interpretar e produzir sentidos outros para as questões nas quais estamos enredadas no campo das políticas curriculares.

\section{Abordagem das lógicas, o afeto e a política}

A abordagem das lógicas opera com três lógicas interligadas: as lógicas sociais, as lógicas políticas e as lógicas fantasmáticas. Os autores defendem, do ponto de vista metodológico, ser necessário afirmar que uma pesquisa a partir das lógicas implica afastamento da noção de subsunção (GLYNOS; HOWARTH, 2007), bem como da mera descrição e afirmação da relação entre diferentes elementos teóricos e empíricos. A subsunção é uma noção que se mostra evidente quando, por exemplo, opera-se com a ideia de tomar a lógica social como paradigma a partir do qual se possa compreender todos fenômenos. Ou ainda, quando em uma investigação, diante de conceitos e objetos de investigação, opera-se de modo que os últimos sejam englobados ao primeiro.

A lógica social informa acerca de uma imensidade de possíveis efeitos que resultam de sistemas de discursos (práticas) entendidos como particulares instituídos. Considerando que a teoria do discurso enfatiza a primazia do político frente ao social, em grande parte a partir da rejeição do caráter necessário dessa prática e assumindo a centralidade na contingência radical, não há qualquer precedência, qualquer determinação causal ou qualquer possibilidade de reducionismo. Mais do que as implicações que o afastamento da subsunção de conceitos possa trazer para a investigação, outro ponto que nos mobiliza se refere à ênfase na articulação como alternativa para a construção de uma explanação singular de dado fenômeno (GLYNOS; 
HOWARTH, 2007). A aposta na articulação ganha força, na mesma medida em que a subsunção é rejeitada. Tentando uma aproximação maior com nosso foco neste texto indagamos: será potente explorar os investimentos afetivos como parte de nossa pretensão em continuar nossos questionamentos teórico-estratégicos nas políticas curriculares? Reparem que também estamos nos afastando de um posicionamento que dissocia questões de metodologia e questões teóricas. Glynos e Howarth (2007, p. 210) vão ainda mais além e afirmam que, sob o manto do cientificismo, os sujeitos se engajam em práticas científicas e não somente falham em refletir criticamente sobre seus objetos e métodos de estudo, filiando-se em posições ingênuas de objetivismo, como também reforçam a ideia de que o conhecimento serve somente aos interesses empíricos e instrumentais.

Toda nossa argumentação até aqui busca servir de preparação do terreno para discutir como a lógica fantasmática articula noções que colocam em marcha uma estratégia de investigação capaz de nos ajudar a analisar as lógicas sociais, na mesma medida em que acentua o enquadramento ontológico. Apontamos, como destaque dessa empreitada "metodológica", a oferta de uma gramática (como jogo de linguagem, insistimos nós) alternativa de noções e lógicas que possibilitam construir/articular o caráter político da objetividade social.

O mérito de Jason Glynos e David Howarth, no livro intitulado "Logics of Critical Explanation in Social and Political Theory", é ampliar o debate metodológico em uma perspectiva pós-estrutural, enfrentando a tradição positivista, causalista, cientificista de grande parte das teorias e metodologias. Como fruto desse "diálogo", apostam em quatro proposições teórico-metodológicas para a realização de pesquisas empíricas referenciadas nessa perspectiva, a ver:

[...] Glynos e Howarth (2007) procuraram desenvolver de modo sistemático uma reflexão sobre as implicações (anti)epistemológicas e metodológicas da teoria do discurso, buscando suprir o que alguns, como Torfing (2005), vinham identificando como um déficit metodológico no projeto teórico de Laclau e Mouffe (2001). Esse esforço resultou no delineamento de quatro proposições teórico-metodológicas para a realização de pesquisas empíricas referenciadas nessa perspectiva: i) A eleição de um modelo de pesquisa orientada ao problema [problem driven research], em oposição ao enfoque na metodologia ou na teoria; ii) A adoção de um modelo de ciclos de racionalidade retrodutiva como constituinte tanto da lógica da descoberta quanto da lógica da justificação nas ciências humanas e sociais; iii) A adoção do conceito de lógicas - sociais, políticas e fantasmáticas - como unidades explicativas para a interpretação dos fenômenos de formação, sustentação e mudança das identidades e práticas sociais; e iv) A utilização da perspectiva da articulação - em contraste com as noções de representação ou subsunção como modelo de relação entre as categorias e formulações teóricas e analíticas e os demais significantes e discursos presentes no campo e/ ou enunciados pelos próprios sujeitos sociais. As indicações apresentadas estabelecem uma 
distinção clara entre o modelo de construção do conhecimento científico requerido pela concepção ontológica da teoria do discurso e os modelos epistemológicos (neo)positivistas ainda fortemente influentes na educação e nas ciências humanas. (OLIVEIRA et al., 2013, p. 1332)

Este excerto, além de apresentar "as proposições teórico-metodológicas", também destaca o esforço dos autores em construir possibilidades teórico-estratégicas da teoria discurso a partir da ontologia pós-estruturalista. Essa ontologia busca dar suporte ao caráter discursivo e contingente de qualquer identidade ou objeto, bem como dá suporte às lógicas sociais, políticas e fantasmáticas.

Segundo os autores da Escola de Essex (GLYNOS; HOWARTH, 2007), as lógicas acima mencionadas, a partir de seu caráter mutuamente contaminado, contribuem para "a efetiva" possibilidade de expressar processos de mudanças e de estabilização que ganham passagem em uma teoria da hegemonia. Glynos e Howarth são enfáticos em apresentar o conceito de lógicas como capazes não somente de prover os objetos de investigação crítica como suas condições de possibilidade, mas também como aqueles que fornecem suas condições de impossibilidade (IDEM, 2007, p. 153). Tendo em vista a intrínseca relação dos conceitos das três lógicas à contingência das relações sociais, torna-se possível responder como determinadas escolhas foram realizadas e/ou impedidas de se constituírem. A seguir, apresentaremos cada uma das três lógicas.

As lógicas sociais referem-se a regras, mas regras em articulação com regimes. Pode-se afirmar que essa articulação de regras com regimes favorece tentativamente depurar propósito, forma ou conteúdo das lógicas. As práticas sociais sempre extrapolam quaisquer sistemas de regras. Isso porque referem-se às infinitas possibilidades e a uma riqueza contextual que não pode ser apreendida (IDEM, 2007, p. 136). A grosso modo, pode-se afirmar que regras, do ponto de vista metodológico, habilitam o investigador a recuperar os sentidos e os possíveis papéis que determinadas práticas exercem. E se estamos considerando as lógicas sociais, importa dizer que essa condição (ficcional) de recuperar sentidos é muito bem-vinda, especialmente em um momento de caracterização de uma prática social particular.

Nessa abordagem, os autores citam como um regime de práticas, a exemplo de um discurso como o Thatcherismo no Reino Unido, pode ser reconhecido por uma série de lógicas sociais entrelaçadas e identificado como a aspiração de liberar a economia capitalista como também a aspirar a demanda por um Estado maior mais restritivo e com menos regulação, ao mesmo tempo mais intensamente regulatório e poderoso (GLYNOS; HOWARTH, 2007, p. 137). Esse discurso compreende um heterogêneo conjunto de práticas conectadas ao bem-estar, aos negócios, com passagens pela legislação, por medidas e metas governamentais locais. 
Segundo os autores, Laclau vai dizer que a lógica social se organiza como uma ampla coerência da prática discursiva, afirmando que "lógica social consiste em seguir regras" e envolve ainda "um rarefeito sistema de afirmações, um sistema de regras desenhado no horizonte no qual alguns objetos são representados enquanto outros são excluídos.” (IDEM, 2007, p.139)

Em suma, pode-se dizer que as lógicas sociais levam em consideração as regras, mas estas precisam ser qualificadas. Assim, as regras não são concebidas como entidades que subsumam práticas e discursos, ou apenas possibilitam a descrição e caracterização dos discursos/práticas. Os autores trazem à baila Wittgenstein para reafirmarem que uma lógica não pode ser separada do contexto empírico no qual funciona; lógicas operam por jogos de linguagem e nas circunstâncias nas quais subsistem. Eles enfatizam ainda um aspecto que vimos colocando de diferentes formas neste artigo: que as lógicas sociais não devem ser vistas como relacionadas a mecanismos causais.

As lógicas políticas vão se focalizar no modo como as práticas sociais e/ou regimes sociais se instituíram. Isso contribui para nossa descrição e análise, tendo em vista que a identidade e a relevância ou não de uma prática social estão estreitamente ligadas ou a sua instituição ou a como se dá seu "apagamento". Desse modo, "O nexo de lógicas é concebido como uma forma de analisar o caráter construído e político das práticas, incluindo a maneira como o status quo é protegido, desafiado e defendido" (GLYNOS; KLIMECKI; WILLMOTT, 2012, p. 298, tradução livre)

Assim, as lógicas políticas empreendem a caracterização da prática ou regime mostrando como eles emergem ou como se sedimentam. Mais uma vez, acompanhando Glynos e Howarth, importa referir que o enquadramento ontológico não pode ser deixado de lado quando abordamos as lógicas políticas. Também precisaremos estar atentos às consequências teórico-estratégicas: se estamos considerando que todas as práticas são práticas de significação, as lógicas políticas vão ser também, em certa medida, lógicas de significação. Em termos de derivação teórica, segundo Glynos e Howarth, as lógicas políticas emergem também da ontologia pós-saussureana da significação, notadamente nas dimensões substitutivas e combinatórias (metáforas e metonímias). Na teoria do discurso de Ernesto Laclau e Chantal Mouffe, tais dimensões podem ser relacionadas às lógicas da equivalência e lógicas da diferença. Como as práticas políticas sempre implicam a construção de novas fronteiras com vistas a desafiar antigas estruturas sociais em nome de um ideal ou princípio, pode-se afirmar que a lógica da equivalência se sobressai. Por outro lado, se há um abalo nas fronteiras, o que se destaca é a lógica da diferença. Em síntese: 
As lógicas políticas de equivalência e diferença compreendem um enquadramento descritivo que deriva de uma compreensão particular do discurso e da importância atribuída aos processos de significação. As lógicas aprimoram nossa abordagem da explicação das ciências sociais, fornecendonos uma gramática conceitual para explicar a dinâmica da mudança social. Ajudam a mostrar como as práticas e regimes sociais são contestados, transformados e instituídos, ampliando assim nossa gramática para além da lógica social. (GLYNOS; HOWARTH, 2007, p. 145, tradução nossa)

Por fim, apresentamos as lógicas fantasmáticas e como essas municiam os sentidos que expressam a aderência já existente ou a que se antecipa à determinada prática social ou regime.

As lógicas fantasmáticas são aqui concebidas como responsivas aos desejos animados por um impulso de recapturar um gozo primordial, ou gozo que é sacrificado pelo sujeito ao entrar na ordem simbólica. Esse sacrifício ontológico se correlaciona diretamente com a premissa pós-estruturalista de que as estruturas simbólicas são inerentemente incompletas, o que implica que o momento político está sempre-já presente como um momento potencial de contestação e mobilização. No entanto, o sacrifício ontológico do gozo é rotineiramente não reconhecido, pois é projetado para os outros e atribuído ao status de "roubado". Na verdade, a noção de 'roubo de prazer' é um motivo muito poderoso na forma como os sujeitos estruturam seu desejo e muitas vezes informa várias tendências de bode expiatório manifestadas no roubo de 'nosso' gozo pelos banqueiros 'gananciosos' e 'imprudentes', por exemplo (cf. Chang \& Glynos 2011). (GLYNOS; KLIMECKI; WILLMOTT, 2012, p. 299)

Aqui começamos a dar um pouco mais de consequência a nossas indagações, ou seja, começamos a argumentar "como" e "por quê" as fantasias dão suporte ao Real, a partir da concepção de sujeito barrado, sujeito da falta, um sujeito cindido desde sempre. Essa condição é o "pagamento" por estarmos imersos no simbólico:

Hay algo que conecta lo individual a lo colectivo, lo subjetivo a lo objetivo, lo universal a lo particular; pero esta no es uma identidad esencial fundamental, una identidad ya realizada o en curso. Es exactamente lo opuesto: es el sujeto, falta simbólica él mismo, el que escinde las concepciones essencialistas de la individualidade; es el mismo sujeto como falta el que introduce la división em la colectividad humana. (STAVRAKAKIS, 2007, p. 70)

O objetivo e o subjetivo são duas faces de uma mesma moeda e expressam um impossível desejo de completude. Essa relação, mutuamente contaminada, captura a imaginação social, funciona articulada à prática política e está marcada pela falta, pela impossibilidade. Tal falta expressa o gozo (jouissance) perdido. A lógica fantasmática está estreitamente ligada ao conceito de gozo e há ainda uma estreita ligação com a fantasia, que não significa uma ilusão da realidade, é bom reiterar (CLARKE, 2012). A fantasia é uma promessa de completude, segundo Yannis Stavrakakis: "No hay nada en lo simbólico que pueda 
brindarnos la solucion para nuestra división, uma salida de este estado de frustración. (2007, p. 76-77). A partir da lógica fantasmática, de acordo com Glynos e Howarth, metodologicamente há abertura para uma leitura (análise) das respostas, uma gramática dessa resistência à mudança nas práticas sociais, são respostas a certa inércia das práticas sociais, como também são respostas que imprimem velocidade e direção, indicando o vetor das práticas políticas.

As três lógicas operam de modo articulado, uma imbricada a outra. Teóricoestrategicamente, podemos dizer que a lógica fantasmática fortalece a dimensão das práticas sociais pela tentativa de colmatar a falta primordial na realidade (IDEM, 2007, p. 146). Nos dizeres lacanianos, as fantasias dão suporte ao que chamamos realidade. As lógicas fantasmáticas também se relacionam com as práticas políticas. Os autores ressaltam que, antes de tudo há que considerar que as lógicas políticas estão ligadas aos momentos de contestação e instituição estabelecidos contingencialmente. Além disso, essas lógicas implicam uma tentativa de defesa ou ataque de uma ordem existente, via construção de antagonismos sociais. Vale um destaque sobre o caráter positivo que a lógica fantasmática (a fantasia) assume em relação à falta constitutiva, fornecendo ao sujeito, à sociedade, um modo de positivar a falta, preenchendo-a, na estrutura.

À guisa de síntese, Glynos e Howarth afirmam que tanto no contex to das práticas sociais como no da práticas políticas, a fantasia opera de modo a encobrir a contingência das relações sociais. Nos discursos, a lógica fantasmática pode ser expressa como o que promete completude assim que o obstáculo nomeado ou implicado seja "transposto" - essa seria a dimensão beatífica da fantasia - ou ainda previne o desastre se o obstáculo se mostrar intransponível - no caso, seria a dimensão horrífica da fantasia. Analisar práticas discursivas a partir da lógica fantasmática pode vir a fornecer contribuições para nossas investigações em uma perspectiva discursiva:

\footnotetext{
Além disso, essas lógicas normalmente se baseiam em narrativas que possuem características distribuídas entre fóruns públicos oficiais e não oficiais. Isso porque as fantasias buscam diretamente conjurar - ou pelo menos pressupor uma união impossível entre elementos incompatíveis. Eles participam de uma lógica do "have your cake and eat it" e, portanto, uma forma dos sujeitos lidar com essa impossibilidade é distribuir o aparecimento de elementos incompatíveis entre os diferentes registros. (GLYNOS; HOWARTH, 2007, p. 147-148, tradução nossa)
}

Do ponto de vista teórico-estratégico, operar também com a lógica fantasmática coloca em andamento o questionamento de como elementos dispersos e, por vezes incompatíveis, (retro)alimentam os discursos. Isso nos oferece argumentos em defesa da importância dos investimentos afetivos para a política uma vez que na investigação dos discursos das políticas 
curriculares há esses elementos dispersos mas estes tendem a passar desapercebidos, por sua condição opaca, vacilante que não se deixam gerir por uma organização cartesiana.

Essa observação nos ajuda a identificar os elementos fantasmáticos da realidade social, pois gera uma regra prática metodológica importante: a evidência empírica que indica a presença de um objeto fantasmático pode muitas vezes ser identificada perguntando se ele resiste ou não à divulgação oficial pública. Além disso, poderíamos dizer que aspectos da realidade social relacionados com o gozo fantasticamente estruturado muitas vezes possuem características contraditórias, exibindo uma espécie de oscilação extrema entre posições incompatíveis. (GLYNOS; HOWARTH, 2007, p. 147-148, tradução nossa)

A nosso ver, aqui está sendo explorada uma consequência "metodológica" potente: "aspectos da realidade social relacionados com o gozo fantasticamente estruturado muitas vezes possuem características contraditórias, exibindo uma espécie de oscilação extrema entre posições incompatíveis". É justamente porque não recuperamos o “objeto perdido” em sua plenitude que nos mantemos suportados fantasmaticamente tanto pela falta como pelo excesso: a promessa de excesso apoia-se na renovação contínua de experiências de falta (STAVRAKAKIS, 2007, p. 240-241). A afirmação de que o “objeto a" é causa do desejo, e não a possibilidade de realização do desejo, faz parte do que poderíamos chamar de dialética do gozo. Essa dialética é utilizada por Stavrakakis (2007) para defender que os investimentos afetivos conferem força (nunca somente forma) a dado objeto de identificação, com vistas a ampliação de seu caráter desejável.

Considerando especificamente a educação, por exemplo, há um discurso recorrente na política curricular para formação de professores ${ }^{3}$ - o discurso do déficit formativo do professor - que expressa esse lugar da falta, ao mesmo tempo em que há também o discurso do excesso - o discurso da "formação baseada em evidências". Esse discurso "do déficit" ganha força em seu duplo gesto: nomeia a falta e coloca no horizonte seu preenchimento. Isso parece ser a dialética do gozo, ou seja, há um investimento afetivo que funciona como promessa de preenchimento desse "déficit" e de tantos outros "déficits", mas contraditoriamente também há no campo discursivo do campo de Formação de Professores um discurso de recusa desse lugar.

As metodologias pós-estruturais (GLYNOS; HOWARTH, 2007; STAVRAKAKIS, 2007), em geral, têm nos ajudado a entender a contingência de algo instituído, mas falham (carecem de consistência) em avaliar a força e seu caráter persistente, em analisar a plasticidade

3 É possível citar o texto da BNC-Formação, mas isso não significa dizer que esse documento é a materialização do discurso ou a única expressão desse discurso. O discurso do déficit formativo do professor é que possibilita a existência de um BNC-formação e a significação atual e de outros tempos da política de formação docente como a política de tamponar esse déficit formativo. 
dessas fixações precárias e provisórias. Enfim, falham em ajudar a compreender porque determinada prática discursiva "gruda" e o modo como "gruda". A fantasia oferece essa aderência, ou seja, oferece o "objeto pequeno a" como a promessa do encontro com o gozo. O investimento afetivo é o que alimenta os processos de identificação e o que possibilita a fixação discursiva. A lógica fantasmática articula assim tanto questões particulares, individuais, como questões do coletivo no qual esse indivíduo está imerso. Vale destacar que a pista a ser seguida não se prende somente a uma necessidade física por alimentação, mas por questões de outras ordens: religiosas, políticas, éticas, culturais que também atuam na de fixação de sentidos.

A lógica fantasmática se debruça sobre como a dialética do gozo funciona na fixação dos sentidos, o que pode ajudar a explicar o modo como os discursos se organizam. Tal dialética pode ser entendida a partir do momento em que a fantasia, em seu funcionamento, visa uma orquestração que estimule ou cause o desejo em sua promessa de tamponar a falta constitutiva decorrente da perda do gozo, desde sempre perdido, com o objeto substituto, o objeto pequeno a. A consequência para nosso investimento teórico-estratégico é ter em conta que os afetos conferem forma, mas também força aos discursos. Os afetos funcionam como um objeto de identificação amplamente desejável e que se deslocam de modo difuso, disruptivo. Além disso outro aspecto concorrente a não perder de vista é que a noção de sujeito do gozo assentase na marca da condição humana - a perda do prazer e o caráter impossível do prazer.

Em linhas mais amplas, a disputa por determinado sentido refere-se tanto ao lugar quanto à força da ação política, como também à força da contingência. Refere-se ainda a abalar o processo contínuo e constante de retirada do político dos processos de sedimentação dos discursos. Num mesmo movimento enfrenta-se um discurso recorrente que tende a reduzir a política a meandros burocráticos e ao que limita espaços para o afeto. Toda essa discussão tem sido potente nas nossas investigações, tendo em vista que investigamos os textos políticos textos com pretensão da objetividade, mas que não cumprem essa condição. Uma preocupação recorrente é como explicar, como colocamos em causa, várias práticas discursivas que acabam por defender aquilo sobre o qual diferentes grupos se posicionam contra. Temos vários exemplos disso, como a reiterada denúncia da separação teoria e prática e os incontáveis discursos em favor de uma centralidade na docência; ou os discursos em defesa da aprendizagem, como se essa pudesse estar atomizada e destacada das articulações entre educação, estudo, currículo, vida, subjetividade. 


\section{Considerações finais}

Neste trabalho tivemos como propósito levantar indagações quanto ao papel do investimento afetivo para a política. Nesse sentido, também afirmamos um negligenciamento do afeto, mesmo em nossas próprias pesquisas, na mesma medida em que toda afirmação da importância de "algo" já está igualmente apontando a negligência do que se afirma. Partimos da ideia de que tal negligência tem relações com a forte tentativa de atribuir um sentido cognitivo às práticas sociais e políticas, expressando reverberações de dimensões cartesianas na forma de pesquisar. Tal concepção deixa efeitos, mas estes não são suficientes para anular as disputas no campo das políticas curriculares. Muitas disputas se mantêm em função da central importância do engajamento com a contingência radical da objetividade social. Uma das perguntas mais frequentes a respeito dos estudos do afeto concerne a como dar consequência a essa empreitada do ponto de vista teórico-estratégico. Acompanhamos Glynos e Howarth quando eles optam pelo afastamento da subsunção e do descritivismo nas investigações e reiteram as práticas articulatórias como capazes de colocar em marcha uma gramática de noções e lógicas.

Nesse sentido, tentamos nos afastar da polarização entre razão e afeto, não só por considerá-la uma questão muito debatida nas Ciências Sociais e Humanas, e até gasta, mas também porque tal questão insiste na dissociação e na hierarquização entre os polos. No campo do Currículo isso não é diferente, ainda que haja vários grupos de pesquisa investindo tanto na negação da supremacia da razão, como também trabalhando para reconectar esses pólos, mesmo mantendo marcas da dissociação negada.

Parece-nos profícuo explorar a lógica fantasmática nas investigações discursivas das políticas curriculares, tanto conceptualmente quanto empiricamente. Com isso enfatizamos os afetos como importante para a política. Tal ênfase se assenta na condição da fantasia ser um suporte da realidade exercendo uma dupla tarefa: a de tamponar a falta constitutiva do Outro e o de se colocar como aquilo que vai recuperar o gozo (desde sempre perdido). Qualquer prática discursiva, qualquer fixação de sentidos passa pelo investimento afetivo que sempre constitui os caminhos discursivos. Isso se dá tanto individualmente quanto coletivamente, assim como por vias objetivas/subjetivas, mais explícitas ou não. O caminho nunca é direto, as relações não são causais como o pensamento cartesiano nos ensinou. Mais do que isso, investigar esse caminhar discursivo deambulante parece ser oportuno, não para iluminar, não para eliminar e não para indicar a saída. Como exploramos amplamente, essas equações já estão dadas no método cartesiano, um método que colocamos sob suspeita. Buscar caminhos para investigar 
os afetos na política nos parece potente para ampliar ainda mais nossa condição de negociação nesse terreno movediço sem a pretensão de sair dele. Assumir e incorporar os afetos, a nosso ver, passa pela aposta em uma concepção de descentramento do sujeito e que opera mais por diferença do que por processos identitários. Como efeitos dessa aposta, com vistas a contribuir para abalar as perspectivas que visam controlar e direcionar as políticas curriculares - não defendemos superações dessas perspectivas, vale insistir - investigamos como os afetos se movimentam, operam por deslocamentos/condensações, e se expressam sem que tenhamos controle. Por exemplo, consideramos que isso pode ser oportuno para entendermos as formações discursivas em torno da profissionalização docente como também as formações em torno do docente como herói. Importante destacar que os investimentos afetivos para manter tais discursos no campo das políticas de formação de professores deslizam de uma cadeia discursiva para a outra. Ora se encaminham para as concepções cientificistas e de valorização técnica do fazer docente, reivindicando pragmatismo, eficácia e eficiência. Ora se desprende disso defendendo uma postura singular, salvacionista, que se afasta dos paradigmas racionais passando a operar em um registro da utopia. Investigar o investimento afetivo que perpassa os meandros dessas disputas pela significação recoloca-nos no debate e valoriza a condição conflituosa das tomadas de decisão.

A fim de trazer uma contribuição da abordagem discursiva para entender o campo das políticas curriculares, consideramos haver muitos aspectos teóricos da psicanálise a serem explorados para subsidiar as investigações. Mas igualmente afirmamos como importante enveredar para a problemática, a dor/alegria que nos mobiliza no campo, de quais são os meandros dessas "escolhas". E, se pudermos, investirmos em narrar os constrangimentos que nos mobilizam ou nos paralisam.

\section{REFERÊNCIAS}

BOVE, Laurent. Sobre o princípio do conhecimento dos afetos em Espinosa: causalidade e esforço sem objeto na Ética III. Departamento de Psicanálise - Sedes Sapientiae Publicações, Jornal Digital Dos Membros, Alunos E Ex-Alunos, 2009.

BIGLIERI, Paula; PERELLÓ, Gloria. Los usos del psicoanálisis em la teoria de la hegemonia de Ernesto Laclau. Buenos Aires: Grama Ediciones, 2012.

CARVALHO, Janete Magalhães; SILVA, Sandra S. KRETLI; DELBONI, Tânia Mara Zanotti G. F.. The Power of Affections in the Curriculum Discursive Practices: Possibilities of 
the Development of a Relationship-Curriculum. Transnational Curriculum Inquiry, 14-23, 2016. http://nitinat.library.ubc.ca/ojs/index.php/tci <acesso em 22 março de 2021.

CLARKE, Matthew. The (absent) politics of neo-liberal education policy. Critical Studies in Education, 53(3), 297-310, 2012.

FINK, Bruce. O sujeito lacaniano. Rio de Janeiro: Zahar, 1998.

BURITY, Joanildo; OLIVEIRA, Gustavo Gilson. Discourse Theory, Psychoanalysis, and Logics of Critical Explanation, Revista Sul-Americana de Ciência Política, v. 6, n. 1, 1-23, 2020.

GILBERT, Jeremy. 'Signifying Nothing: 'Culture', 'Discourse' and the Sociality of Affect' Culture Machine, 6, 2004.

GLYNOS, Jason; HOWARTH, David. Logics of Critical Explanation in Social and Political Theory. London/ New York: Routledge, 2007.

GLYNOS, Jason; HOWARTH, David. Explicação Crítica em Ciências Sociais: a abordagem das lógicas. In: LOPES, Alice C.; OLIVEIRA, Anna L. A. R. M.; OLIVEIRA, Gustavo G. S. de (Org.). A teoria do discurso na pesquisa em educação. Recife: UFPE, 2018. p. 133-67.

GLYNOS, Jason, KLIMECK, Robin, WILLMOTT, Hugh. Cooling Out The Marks.

The ideology and politics of the financial crisis. Journal of Cultural Economy, Vol. 5, No. 3, August, 2012.

GLYNOS, Jason; STAVRAKAKIS, Yannis. Encuentros del tipo real. Indagando los límites de la adopción de Lacan por parte de Laclau. In S. Critchley \& O. Marchart, Laclau:

aproximaciones críticas a su obra. Buenos Aires: Fondo de Cultura Económica, 2008, p. 249-267.

GLYNOS, Jason; STAVRAKAKIS, Yannis. Politics and the unconscious - An interview with Ernesto Laclau. 1755-6341 Subjectivity Vol. 3, 3, 231-244 www.palgravejournals.com/sub/ ; Macmillan Publishers Ltd., 2010.

GREEN, Bill. Engaging Curriculum: Bridging the Curriculum Theory and English Education Divide. London/ New York: Routledge, 2019.

HOWARTH, David. Pluralizing Methods: Contingency, Ethics, and Critical Explanation. https://www.researchgate.net/publication/267301052. 2009.

FINK. Bruce. O sujeito lacaniano: entre a linguagem e o gozo. Rio de Janeiro: Zahar,1998.

LACLAU, Ernesto. La razón populista. Buenos Aires: Fondo de Cultura Económica, 2009. 
LACLAU, Ernesto. Emancipação e diferença. coordenação e revisão técnica geral, Alice Casimiro Lopes e Elizabeth Macedo. Rio de Janeiro: EdUERJ, 2011a, 222p.

LACLAU, Ernesto; MOUFFE, Chantal. Hegemonia e Estratégia Socialista. Buenos Aires: Fondo de Cultura Económica, 2011.

LACLAU, Ernesto. New Refletions on the revolution of our time. London: Verso, 1990.

LOPES, Alice Casimiro. Mantendo o conhecimento na conversação curricular, porém via discurso: um diálogo com Gert Biesta. Revista de Educação (PUC-Camp.), Campinas, 19(2):99-104, maio/ago., 2014.

LOPES, Alice Casimiro. Sobre a decisão política em terreno indecidível. In: Alice Casimiro Lopes; Marcos Siscar. (Org.). Pensando a política com Jacques Derrida - responsabilidade, tradução, porvir. São Paulo: Cortez, 2018a, v. 1, p. 83-116.

LOPES, Alice Casimiro. Políticas de currículo em um enfoque discursivo: notas de pesquisa. In: LOPES, Alice C.; OLIVEIRA Anna Luiza Martins; OLIVEIRA Gustavo Gilson. (Org.). A Teoria do Discurso na Pesquisa em Educação. Recife: Editora da UFPE, 2018b, v. 1, p. 133-167.

LOPES, Alice Casimiro. Articulações de demandas educativas (im)possibilitadas pelo antagonismo ao "marxismo cultural". Archivos Analíticos De Políticas Educativas / Education Policy Analysis Archives, v. 27, p. 109-129, 2019.

LOPES, Alice Casimiro; BORGES, Veronica. Formação docente, projeto impossível. Cadernos de Pesquisa (Fundação Carlos Chagas. Impresso), v. 45, p. 486-507, 2015.

LOPES, Alice Casimiro; MACEDO, Elizabeth. Currículo e cultura: o lugar da ciência. In: José Carlos Libâneo; Nilda Alves. (Org.). Temas de pedagogia: diálogos entre didática e currículo. São Paulo: Cortez, 2012, v. 1, p. 152-166

MACEDO, Elizabeth; MILLER, Janet L.. Políticas públicas de currículo: autobiografia e sujeito relacional. Práxis Educativa (Uepg. Online), v. 13, p. 948-965, 2018.

MATUS, Claudia. Los Usos Del Afecto En El Currículum Escolar, Belo Horizonte:

Educação em Revista. v.32, n.02, p. 111-130. Abril-Junho 2016.

MILLER, Janet. Teorização do currículo como antídoto contra/na cultura da testagem, Revista e-Curriculum. São Paulo, v. 12, n. 03 p. 2043 - 2063 out./dez. 2014.

OLIVEIRA, Gustavo Gilson; OLIVEIRA, Anna Luiza; MESQUITA, Rui (2013). A Teoria do Discurso de Laclau e Mouffe e a Pesquisa em Educação, Educação e Realidade, Porto Alegre, v. 38, n. 4, out/dez. pp. 1327-1349.

PINAR, William. International handbook of curriculum research. New Jersey: Lawrence Erlbaum, 2003. 
SALTER, Leon A. Populism as a fantasmatic rupture in the post- political order: integrating Laclau with Glynos and Stavrakakis, Kōtuitui: New Zealand Journal of Social Sciences

Online, 11:2, 116-132, 2016.

STAVRAKAKIS, Yannis. Lacan y lo politico. Buenos Aires: Prometeo, 2007.

STAVRAKAKIS, Yannis. The Lacananian Left. Edinburgh: Edinburgh University Press, 2006.

VEIGA-NETO, Alfredo. MACEDO, Elizabeth. Estudos do Currículo: como lidamos com os conceitos de moderno e pós-moderno? ETD - Educação Temática Digital, Campinas, v.9, n.esp., p. 234-252, out., 2008.

ZIZEK, Slavoj. Mas allá del analisis del discurso. In: E. Laclau, Nuevas reflexiones sobre la revolucion de nuestro tiempo. Buenos Aires: Ediciones Nueva Visión. (1990/2000), p. 257267.

\section{SOBRE AS AUTORAS:}

\section{Veronica Borges}

Doutora em Educação na Universidade do Estado do Rio de Janeiro (UERJ); Pós-Doutorado (em andamento) na Universidade de Lisboa (ULisboa), atuando no Programa de Pós-graduação em Educação da Universidade do Estado do Rio de Janeiro (UERJ), Brasil. Correio eletrônico: borges.veronica@gmail.com

(iD) https://orcid.org/0000-0002-0011-1769

\section{Alice Casimiro Lopes}

Doutora em Educação na Universidade Federal do Rio de Janeiro (UFRJ) com Pós-Doutorado na Universidade Estadual de Campinas (Unicamp), atuando no Programa de Pós-graduação em Educação da Universidade do Estado do Rio de Janeiro (Uerj). Grupo de Pesquisa Políticas de Currículo e Cultura. Bolsista de Produtividade do CNPq nível 1 A, Cientista do Nosso Estado Faperj e Procientista Faperj/Uerj. Correio eletrônico: alicecasimirolopes@gmail.com

(iD) https://orcid.org/0000-0001-9943-9117 